\title{
Building Lptp Vpn Network and User Management Using Fuzzy Logic Based on Age and Utilization of The Dude for Network Monitoring (Membangun Jaringan Vpn L2tp Dan User Management Menggunakan Logika Fuzzy Berdasarkan Umur Serta Pemanfaatan The Dude Untuk Monitoring Jaringan)
}

\author{
Fakhri Fakhlur Rahman ${ }^{1}$, Sahari $^{3}$, Riska Robianto ${ }^{2}$ \\ Program Studi Sistem Komputer ${ }^{1}$ \\ Fakultas Ilmu Komputer Universitas Putra "YPTK" Padang ${ }^{2}$ \\ Fakultas Ilmu Komputer Universitas Putra "YPTK" Padang ${ }^{3}$ \\ *E-mail: fakhrifakhlurrahman@gmail.com, sahari@upiyptk.ac.id, riskarobianto@upiyptk.ac.id
}

\begin{abstract}
Abstrak
Penelitian ini bertujuan untuk membangun sebuah jaringan VPN, mengembangkan pemanfaatan The Dude sebagai monitoring jaringan dan manajemen user pembagian bandwithnya menggunakan logika fuzzy serta menggunakan ROUTERBOARD MIKROTIK sebagai pengendali proses. Manfaat yang di dapat dari pengembangan alat ini adalah untuk mempermudah admin atau pemilik usaha dalam proses pengontorolan dan pematauan pada hotspot. Penelitian ini dilakukan dengan merancang, membuat dan mengimplementasikan komponen-komponen sistem yang meliputi routerboard sebagai pengendali proses, acces point sebagai pemancar sinyal $2.4 \mathrm{Ghz}$, aplikasi The Dude sebagai monitoring jaringannya dan manajemen user serta vpn sebagai media penghubung dari jaringan publik ke jaringan lokal hotspot. Hasil penelitian ini menunjukkan alat yang dibuat dapat berfungsi dengan baik dan dikembangkan untuk skala yang lebih besar.
\end{abstract}

Kata kunci: Fuzzy Logic, Hotspot, L2TP, Mikrotik, Routerboard, The Dude, VPN.

\begin{abstract}
This study aims to build a VPN network, develop the use of The Dude as network monitoring and user management of bandwidth sharing using fuzzy logic and using MICROTIC ROUTERBOARD as process controller. The benefit of developing this tool is to facilitate the admin or business owner in the process of monitoring and monitoring on hotspots. This research was conducted by designing, making and implementing system components which include routerboard as process controller, access point as $2.4 \mathrm{Ghz}$ signal transmitter, The Dude application as network monitoring and user management as well as VPN as connecting media from public network to local hotspot network. The results of this study indicate that the tools made can function well and are developed on a larger scale.
\end{abstract}

Keywords: Fuzzy Logic, Hotspot, L2TP, Mikrotik, Routerboard, The Dude, VPN.

\section{Pendahuluan}

Virtual Private Network (VPN) sendiri merupakan sebuah teknologi komunikasi yang memungkinkan adanya koneksi dari jaringan publik serta menggunakannya bagaikan menggunakan jaringan lokal dan juga bahkan bergabung dengan jaringan local itu sendiri. Dengan menggunakan jaringan publik ini, maka user dapat mengakses fitur-fitur yang ada di dalam jaringan lokalnya, mendapatkan hak dan pengaturan yang sama bagaikan secara fisik kita berada di tempat dimana jaringan lokal itu berada. 
Salah satu service VPN yang terdapat di Mikrotik adalah L2TP (Layer 2 Tunneling Protocol), L2TP merupakan pengembangan dari PPTP ditambah L2F. Network security Protocol dan enkripsi yang digunakan untuk autentikasi sama dengan PPTP, Biasanya untuk keamaanan yang lebih baik, dengan adanya VPN ini pengamanan data dan jaringannya lebih aman dibandingkan PPTP Tunnel.

Umur adalah satuan waktu yang mengukur waktu keberadaan suatu benda atau makhluk, baik yang hidup maupun yang mati. Semisal, umur manusia dikatakan lima belas tahun diukur sejak dia lahir hingga waktu umur itu dihitung. Oleh karna itu, umur diukur dari ia lahir sampai pada hari ini ataupun sampai ia meninggal dunia nanti.

Logika Fuzzy adalah metode yang dipakai untuk mengatasi hal yang tidak pasti pada masalah-masalah yang mempunyai banyak jawaban. Pada dasarnya logika fuzzy merupakan logika bernilai banyak/ multivalued logic yang mampu mendefinisikan nilai diantara keadaan yang konvensional seperti benar atau salah, ya atau tidak, putih atau hitam dan lain-lain. Penalaran Logika Fuzzy memnyediakan cara untuk memahami kinerja system dengan cara menilai input dan output system dari hasil pengamatan. Logika Fuzzy menyediakan cara untuk menggambarkan kesimpulan pasti dari informasi yang samar-samar, ambigu dan tidak tepat. Dengan adanya logika fuzzy penulis menginginkan bisa membagi management bandwith user hotspot secara maksimal sesuai dengan umur yakninya anak-anak, remaja, dewasa dan tua.

The Dude ialah aplikasi buatan mikrotik yang berfungsi untuk memonitor jaringan komputer. The dude dapat melakukan scanning otomatis pada semua perangkat yang terhubung pada subnet jaringan tertentu. Hasil scanningnya berupa gambar peta konfigurasi jaringan yang menggambarkan kondisi jaringan apakah sedang up/down, the dude juga dapat menampilkan transfer rate antar perangkat di jaringan, jadi dapat memantau traffic yang berjalan di jaringan kita secara realtime. Dengan adanya the dude penulis menggunakannya untuk monitoring semua jaringan yang terhubung pada rauter yang digunakan.

\section{Tinjauan Literatur}

\subsection{Internet}

Internet adalah interkoneksi jaringan komputer skala besar, yang dihubungkan menggunakan protokol khusus. Cakupan internet adalah satu dunia bahkan tidak menutup kemungkinan antarplanet. Koneksi antar jaringan komputer dapat dilakukan berkat dukungan protokol yang khas, yaitu TCP/IP (Transmission Control Protocol/Internet Protocol)[7].

\subsection{Hotspot}

Hostpot merupakan penyedia akses internet secara gratis dengan media nirkabel. Hal ini seiring dengan semakin banyaknya pengguna laptop, notebook, komputer tablet, atau ponsel yang mendukung fitur Wi-Fi. Ketika mengunjungi area hotspot tersebut, para pengguna bias melakukan koneksi ke internet. Tempattempat yang menyediakan fasilitas Wi-Fi atau area hotspot diantaranya adalah kampus, kafe, restoran, tempat tunggu bandara, perpustakaan, mal, kantor pemerintahan, rumah sakit, dan hotel[3].

\subsection{VPN L2TP}

L2TP merupakan tunneling protocol yang memadukan dua buah tunneling protokolyaitu Layer 2 Forwarding milik Cisco dan PPTP yang dimiliki Microsoft. L2TP umumnya digunakan untuk membuat Virtual Private Dial Network (VPDN) yang dapat membawa semua jenis protokol komunikasi di dalamnya dan biasanya menggunakan port 1702 dengan protokol UDP. Terdapat dua model tunnel yang dikenal, yaitu compulsory dan voluntary. Perbedaan utama keduanya terletak pada endpoint tunnelnya. Pada compulsory tunnel, ujung tunnel berada pada ISP, sedangkan pada voluntary ujung tunnel berada 
pada client remote[16].

\subsection{FUZZY LOGIC}

Telah disinggung bahwa tujuan fuzzy pengontrolan adalah untuk meniru aksi operator manusia atau untuk membuat keputusan seperti manusia dengan menggunakan pengatahuan mengenai mengontrol sebuah sistem targer(tanpa mengetahui modelnya). Ini dicapai dengan aturan fuzzy dasar adalah tempat dimana pengetahuan dan pengelaman perancang harus secara benar diinterpretasikan dan diorganisasikan kedalam himpunan aturan tepat[2].

\subsection{THE DUDE}

The Dude adalah program dengan tampilan dan penggunaan yang mudah dari sebuah NMS (Network Monitoring and Management System). The Dude didesain untuk mewakilkan struktur sebuah jaringan komputer yang memungkinkan user untuk membuat skema jaringan yang ada baik secara manual atau pun menggunakan automatic network discovery tool. Kedalam bentuk grafik yang mudah dimonitor serumit apapun jaringan tersebut. The Dude juga memungkinkan untuk memonitoring services yang berjalan pada tiap network host, dan memberi peringatan pada setiap perubahan statusnya[1].

\section{Metodologi}

Adapun metode penelitian yang dilakukan sebagai adalah berikut:

a. Penelitian alat

Pada penelitian alat ini dilakukan pemilihan alat terkait sesuai dengan alat yang dibuat serta mengetahui Hotspot dapat diakses oleh pengguna, untuk menganalisis masalah, serta memperoleh informasi yang dibutuhkan. Serta bagaimana Hotspot dan VPN tersebut dapat bekerja sesuai dengan fungsinya.

b. Riset Perpustakaan

Riset perpustakaan ini dilakukan dengan cara membaca, membahas, meringkas dan membuat kesimpulan dari buku-buku dan jurnal tentang Hotspot dan VPN, serta bahasa pemerograman yang berkaitan dengan analisa dan perancangan Membangun Jaringan Vpn L2tp Dan User Management Menggunakan Logika Fuzzy Berdasarkan Umur Serta Pemanfaatan The Dude Untuk Monitoring Jaringan Hotspot untuk mendapatkan bahan-bahan yang secara ilmiah dapat dijadikan landasan dalam menyusun penelitian ini.

\subsection{Analisa}

Berdasarkan identifikasi masalah di atas, peneliti melakukan analisa data terlebih dahulu. Hal ini bertujuan agar pemecahan masalah dapat mengasilkan sebuah solusi yang baru.

\subsection{Perancangan Sistem}

Perancangan dalam Penelitian membuat Membangun Jaringan Vpn L2tp Dan User Management Menggunakan Logika Fuzzy Berdasarkan Umur Serta Pemanfaatan The Dude Untuk Monitoring Jaringan Hotspot ini didasari oleh beberapa pertimbangan-pertimbangan tertentu. Alat media ini harus memiliki kriteria seperti:

a. Aplikasi yang digunakan untuk mendapatkan hasil data umur menggunakan metode fuzzy pada alat ini adalah Delphi. 
b. Untuk melakukan pemantauan dari manapun admin berada dengan memanfaatkan VPN dan The Dude.

c. Harga yang murah dan terjangkau oleh masyarakat.

d. Komponen standar yang digunakan mudah di dapat.

e. Komponen yang dirancang mudah dibuat. Mudah dalam pemeliharan dan perawatannya.

\subsection{Pengujian Sistem}

Adapun Perencanaan penggunaan alat Membangun Jaringan Vpn L2tp Dan User Management Menggunakan Logika Fuzzy Berdasarkan Umur Serta Pemanfaatan The Dude Untuk Monitoring Jaringan Hotspot adalah sebagai berikut:

1. Persiapan awal di lakukan dengan menyiapkan alat, serta Komponen pembantu yang digunakan.

2. Proses penggunaan The Dude ialah dengan cara mengintal aplikasi tersebut dengan smartphone maupun perangkat komputer lainnya, supaya mempermudah admin dalam memantau jaringannya.

3. Menghitung Kuantitas jumlah user yang dapat terkoneksi ke Hotspot serta kualiatas sinyal pada Jaringan VPN maupun Hotspot.

\subsection{Implementasi Sistem}

Implementasi sistem merupakan tahap meletakan sistem sehingga siap untuk dioperasikan. Implementasi bertujuan untuk mengkonfirmasi modul-modul perancangan, sehingga pengguna dapat memberi masukan kepada pengembangan sistem. Pada tahap ini perancangan sistem dilakukan dengan menggunakan bahasa pemrograman Delphi.

\section{Hasil dan Diskusi}

\subsection{Context Diagram}

Sub bab ini merupakan penjabaran setiap externat entity secara keseluruhan yang digambarkan melalui context diagram. Context diagram merupakan pendefenisian terhadap sistem yang akan dirancang yang bersifat menyeluruh. Context diagram ini digunakan untuk memudahkan dalam proses penganalisaan sistem yang dirancang secara keseluruhan.

Context diagram berfungsi sebagai media, yang terdiri dari suatu proses dan beberapa buah external entity. Context diagram yang dimaksud dapat dilihat pada gambar 4.1 dibawah ini

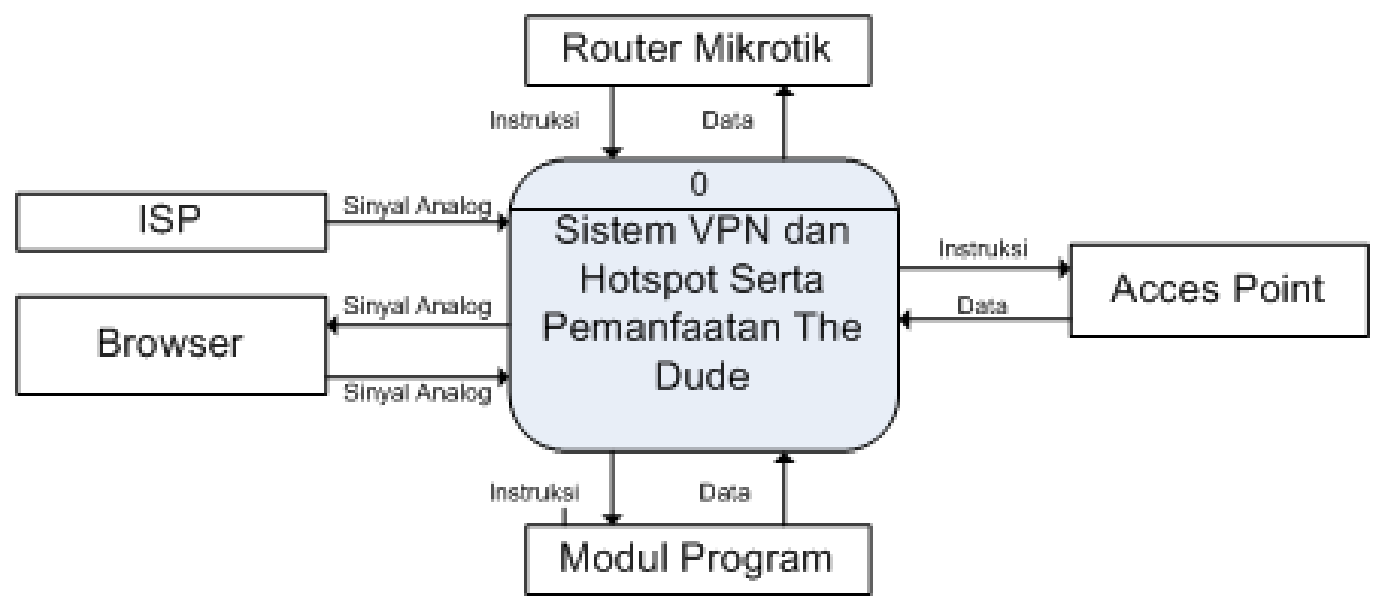




\section{Gambar 4.1Context Diagram Alat}

\subsection{Data Flow Diagram}

Data flow diagram adalah aliran data dari alat yang dibuat. Data flow diagram yang digunakan adalah data flow diagram level 0 karena hanya satu sistem saja yang dikembangkan. Untuk lebih jelasnya dapat dilihat pada gambar 4.2

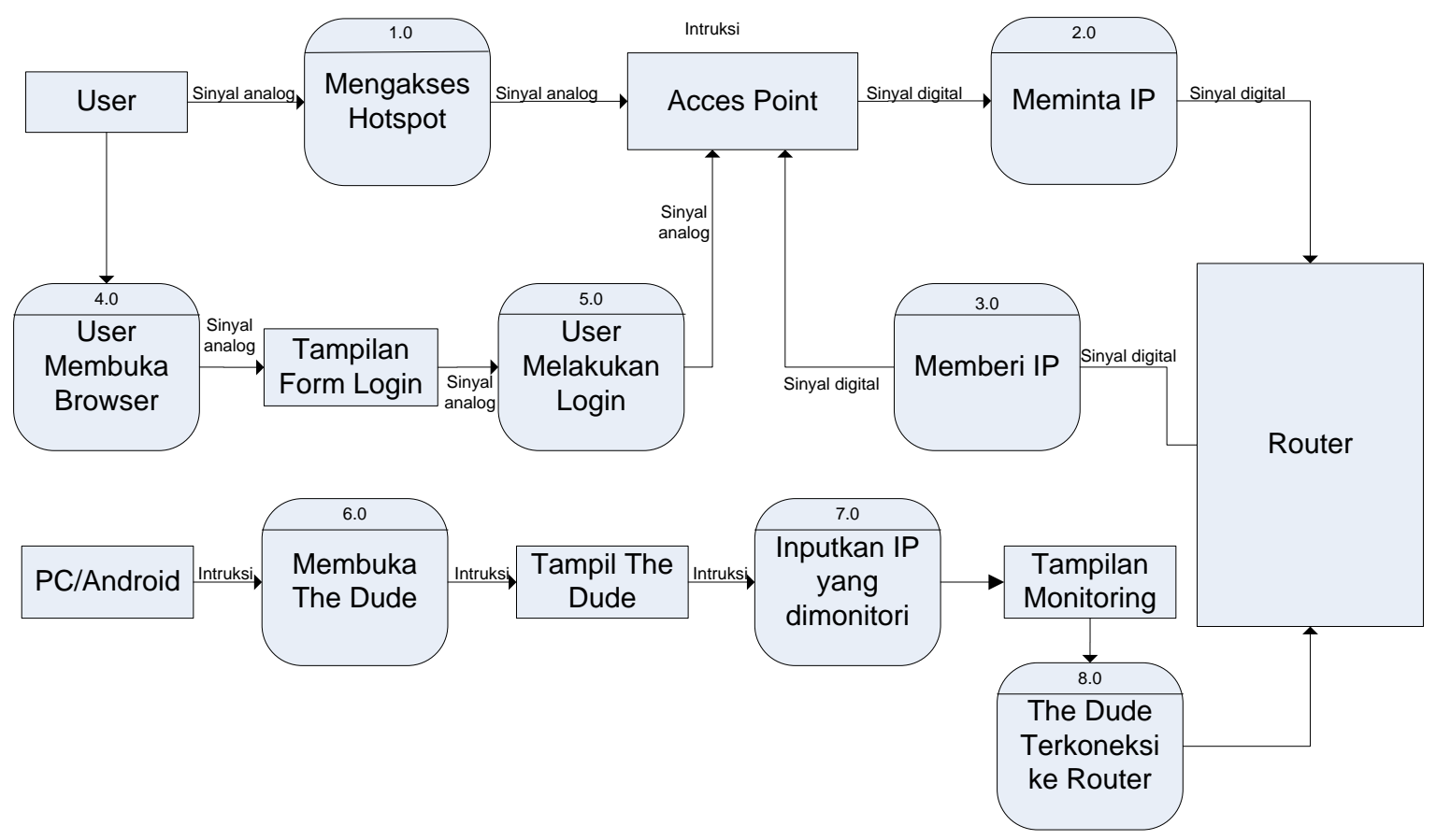

Gambar 4.2 Data Flow Diagram

\subsection{Topologi keseluruhan}

Topologi merupakan gambaran bagaimana perjalanan data atau informasi berpindah dalam sebuah jaringan adalah sebagai berikut, pada gambar 4.3 


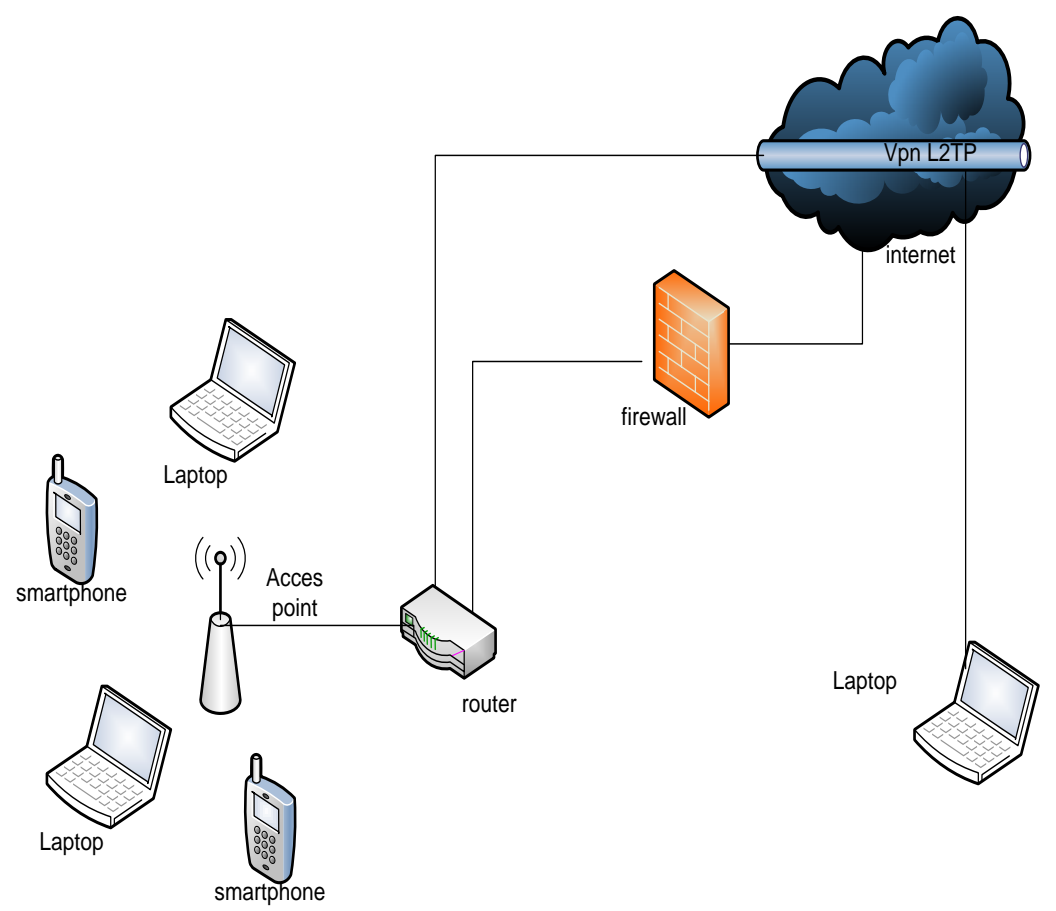

Gambar 4.3 Topologi Keseluruhan

Pada topologi di atas dapat dilihat sususan sebagai berikut:

a. Port pada router 3 ke Acces point.

b. USB pada Router sebagai reciver dari sumber internet.

c. Perangkat clietnt atau user terhubung ke acces point scara wireless.

d. Terdapat Firewall untuk melindungi jaringan local hotspot.

e. Melalui VPN perangkat dapat mengakses dan menggunakan jaringan private pada router.

Fungsi Hotspot adalah sebagai jalur khusus atau tunneling agar admin mendapat hak akses The Dude.

\subsection{Pengujian Rangkaian Keseluruhan}

Pengujian dari sistem ini dapat dilakukan dengan langkah-langkah sebagai berikut:

1. Pastikan perangkat terhubung ke hotspot, setelah teruhubung buka browser dan buka link http://frhotspot.ti maka akan muncul tampilan halam login. Seperti pada gambar 5.11 berikut ini. 


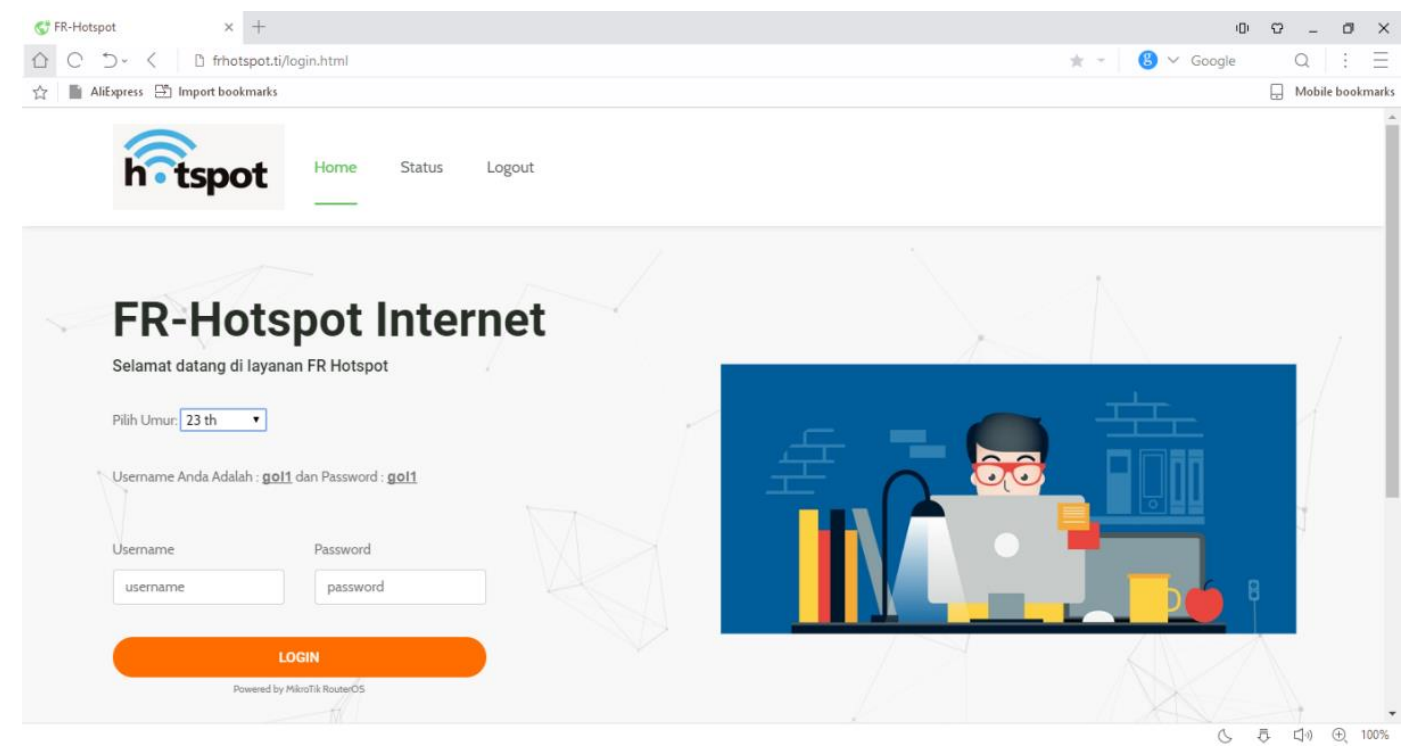

\section{Gambar 5.11 Halaman Login Hotspot}

2. Pilih Umur pengguna saat ini maka akan menampilkan username dan paswordnya, setalah itu inputkan username dan pasword yang telah disediakan lalu klik login hingga tampil seperti gambar 5.12.

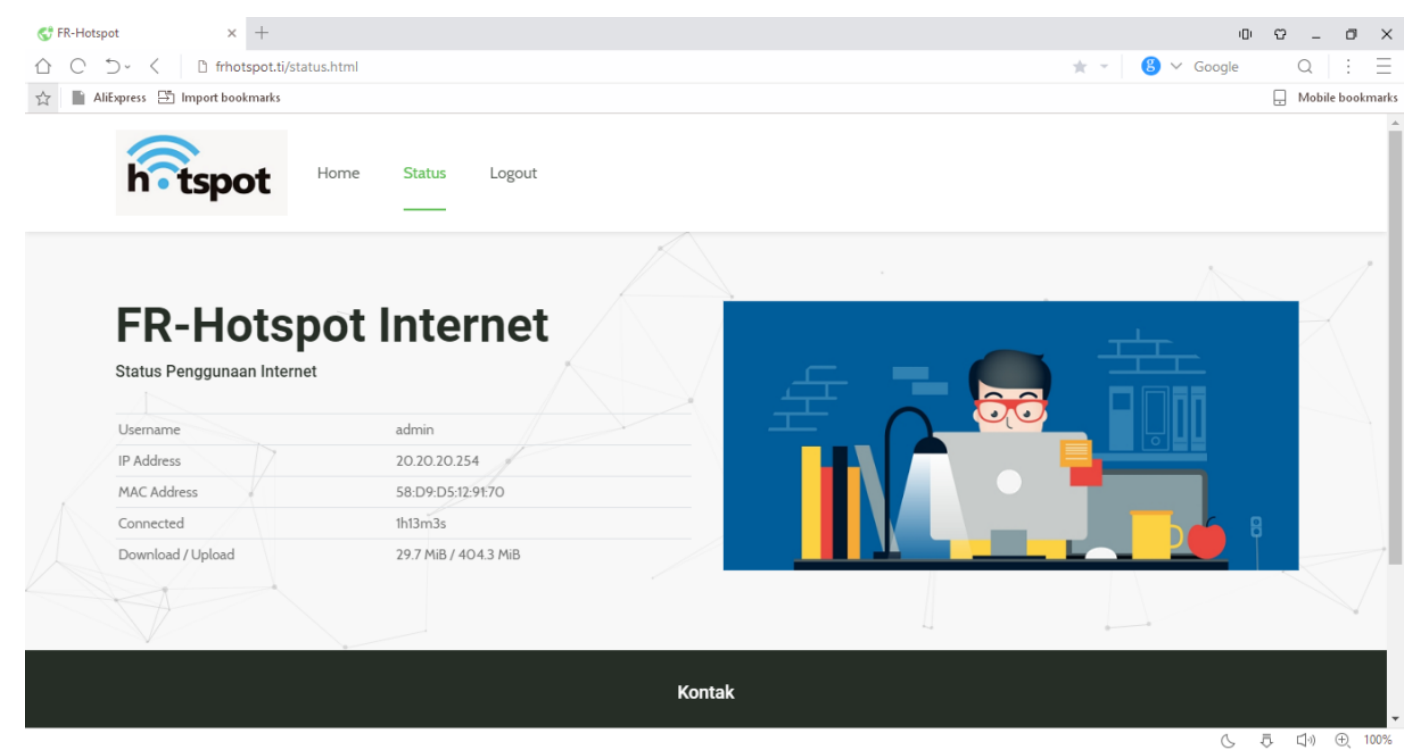

Gambar 5.12 Halaman Status Hotspot

3. Selanjutnya adalah pengujian The Dude Mikrotik, Buka The Dude Mikrotik hingga tampil seperti gambar 5.12, inputkan bagian server dengan IP sumber internet, isi username dengan admin dan pasword kosong lalu klik connet. 


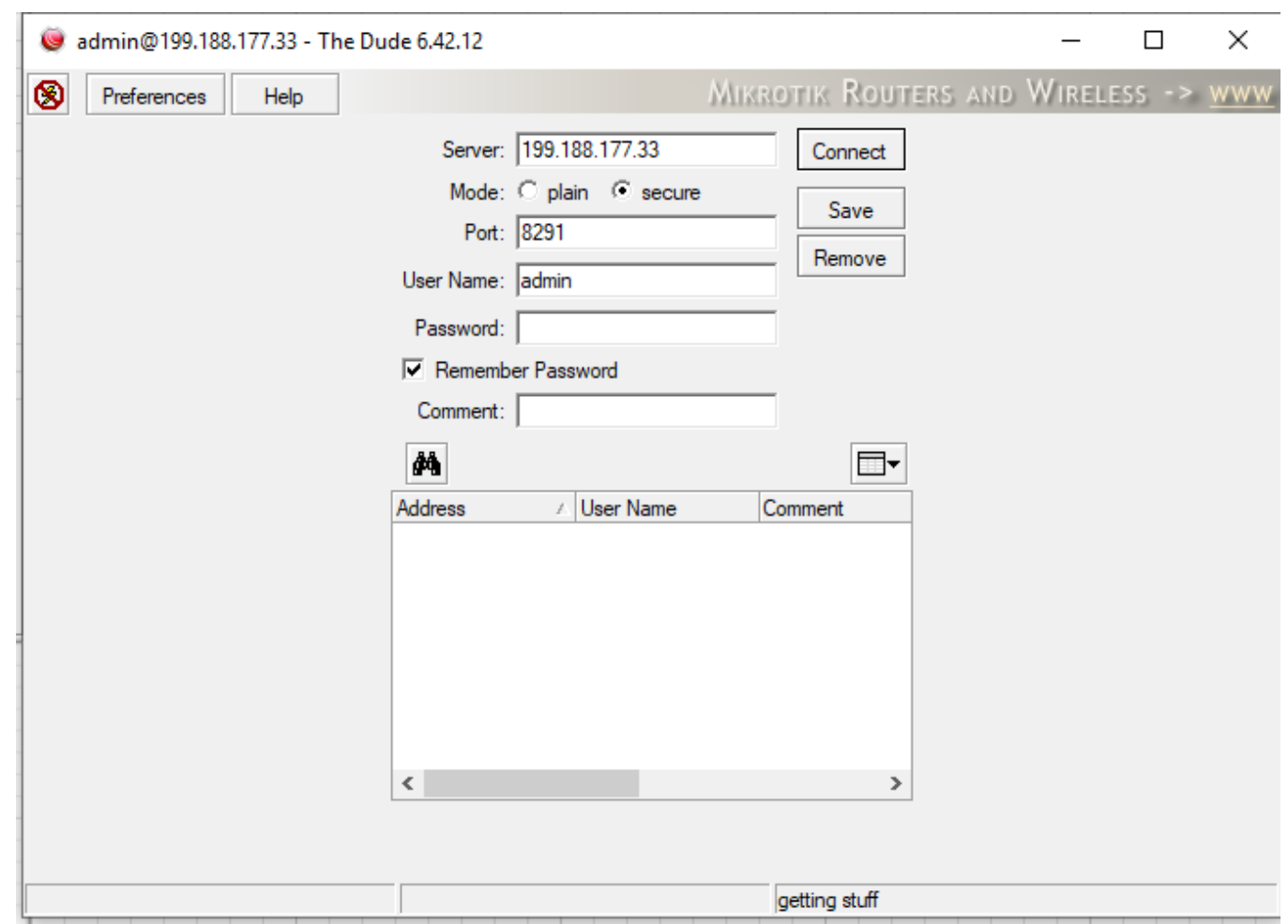

Gambat 5.13 Tampilan Login The Dude

4. Setelahmya kita bisa mengatur the dude untuk monitori jaringan yang kita inginkan dengan cara klik menu Discover lalu inputkan ip yang akan dimonitori pada kolom scan network seperti gambar 5.13 lalu klik Discover hingga tampil seperti gambar 5.14.

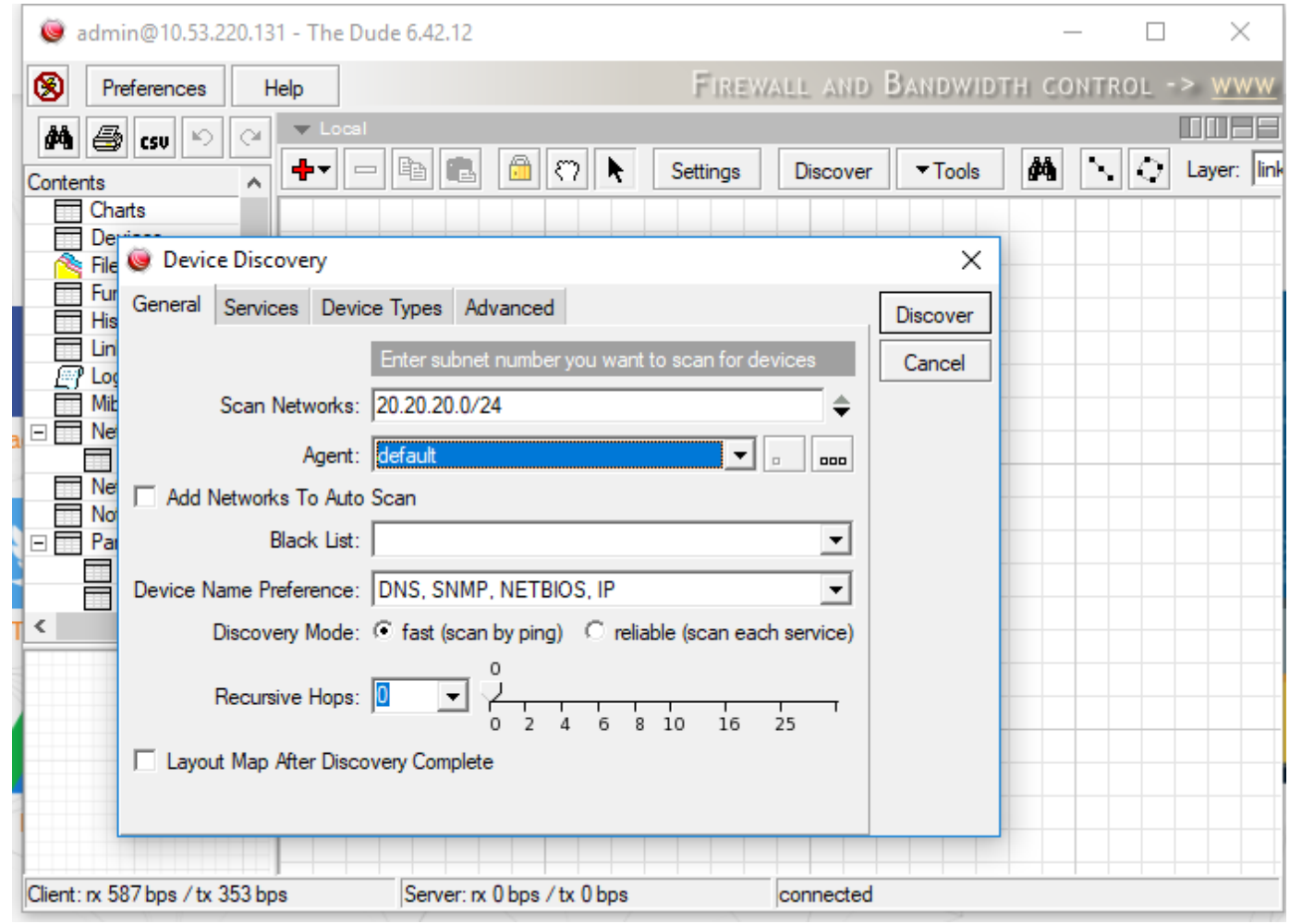

Gambar 5.14 Tampilan Network yang akan dimonitori 


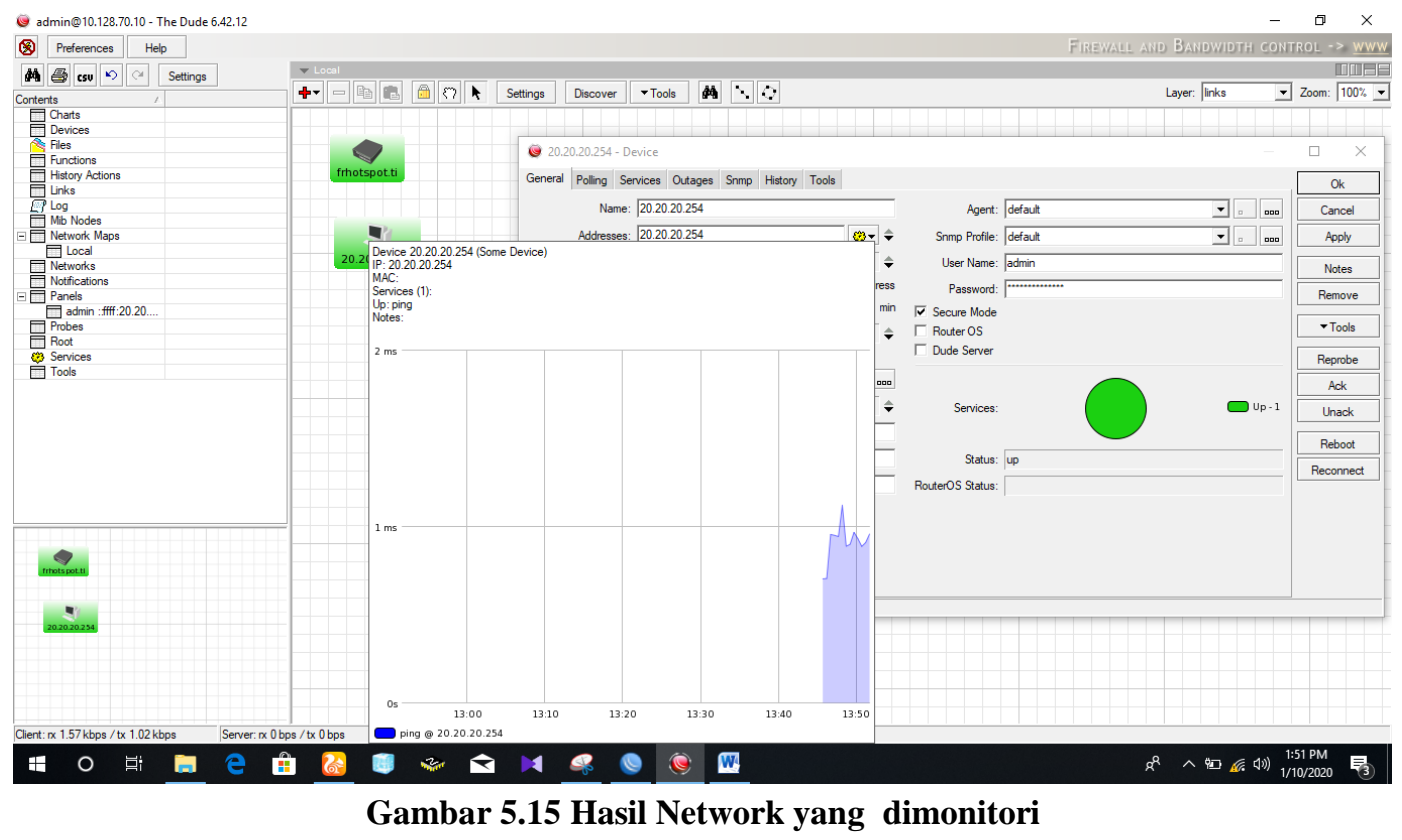

\section{Kesimpulan}

Berdasarkan penjelasan yang tertera pada bab-bab sebelumnya, maka dapat diambil kesimpulan sebagai berikut :

1. Jaringan VPN L2TP merupakan sebuah jaringan yang digunakan jaringan akses pribadi dan pengamanan VPN-nya lebih terjamin dikarnakan menggunakan IPSec.

2. Managemen Bandwith user hotspot menggunakan logika fuzzy dalam pembagian bandwithnya yang didukung dengan bahasa pemprograman delphi berdasar umur user/pengguna.

3. Aplikasi The Dude digunakan untuk monitori jaringan yang terhubung pada router secara realtime sehingga admin dapat mengontrol jaringan tersebut.

4. Media Hotspot ini dapat membantu masyarakat mendapatkan akses internet untuk memperoleh informasi yang diinginkan.

5. Sistem ini dapat menumbuhkan minat penulis dan pembaca untuk melakakukan wirausaha dibidang jaringan.

\section{Referensi}

[1] Adi Widodo. Implementasi Monitoring Jaringan Komputer Menggunakan Dude. ISSN: 1979-1495.

[2] Dr. Ir Saludin Muis,M.Kom. Teori Fuzzy; Konsep dan aplikasi. 2018. Teknosain.

[3] Eko Priyo Utomo Wireless Networking. 2012. Yogyakarta : Andi.

[4] Fajar Mochammad Wicaksono dan Hidayat. Mudah Belajar Mikrokontroler Arduino. 2017. Bandung.

[5] MADCOMS. Membangun Sistem Jaringan Komputer untuk Pemula. 2015. Andi.

[6] MADCOMS. Panduan Lengkap Membangun Sendiri Jaringan Komputer. 2015. Andi.

[7] Sofana Iwan. Membangun Jaringan Komputer. 2013. Bandung. 
[8] Sutabri Tata. Analisa Sistem Informasi. 2012. Yogyakarta: Andi.

[9] Towidjojo Rendra. Mikrotik Kung Fu : Kitab 1. 2016. Jasakom.

[10] Towidjojo Rendra. Mikrotik Kung Fu : Kitab 2. 2016. Jasakom.

[11] Towidjojo Rendra. Mikrotik Kung Fu : Kitab 3. 2016. Jasakom.

[12] Towidjojo Rendra. Mikrotik Kung Fu : Kitab 4. 2016. Jasakom.

[13] Triwiyatno Aris. Buku Ajar Sistem Kontrol Analog. 2012. Semarang.

[14] Trafena Febi Talika. Jurnal Manfaat Internet Sebagai Media Komunikasi Bagi Remaja Di Desa Air Mangga Kecamatan Laiwui Kabupaten Halmahera Selatan. Volume V. No.1. Tahun 2016.

[15] Wahana Komputer. Delphi 2010 Programing. 2010. Andi.

[16] Hadi, A. F. (2017). Analisis Data Mining Untuk Menentukan Variabel-Variabel Yang Mempengaruhi Kelayakan Kredit Kepemilikan Rumah Menggunakan Teknik Klasifikasi. Komputer Teknologi Informasi, 4(1).

[17] Wa Ode Zamalia, L.M. Fid Aksara, dan Muh. Yamin, Analisis Perbandingan Performa QoS, PPTP, L2TP, SSTP dan IPSEC Pada Jaringan VPN Menggunakan Mikrotik, ISSN: 2502-8928 (Online). 